\title{
A Remote Laboratory to Promote the Interaction between University and Secondary Education.
}

\author{
Ramon Bragós, Benjamín Sánchez Terrones, Aleix \\ Guasch \\ ETSETB, Universitat Politècnica de Catalunya (UPC), \\ Barcelona, Spain \\ rbb@eel.upc.edu
}

\author{
Francesc Garófano \\ Department of Education, Generalitat de Catalunya, \\ Barcelona, Spain \\ fgarofan@xtec.cat
}

\begin{abstract}
LabRS is a remote laboratory developed in Telecom BCN, the Telecom and Electronics Engineering School of the UPC with the key participation of a Secondary Education Technology teacher. Students and teachers can access to real experiments in the electronics and physics areas using a web browser. The remote experiments have been designed to partially cover the technology curriculum in the last two high school years with a triple goal: (1) to enrich the set of laboratory experiences available in High Schools, (2) to provide a clear example of the possibilities of internet-based technologies and (3) to promote the interaction between University and Secondary Education. Currently, there are 13 different experiments available. A pilot evaluation experience was carried out, in collaboration with 7 High Schools and around 100 students participating. In the experience assessment, the students gave a mark of 3.8/5 and the teachers of $4.4 / 5$.
\end{abstract}

Keywords- Remote laboratory; Secondary Education; Student engagement.

\section{INTRODUCTION}

Engineering studies, and more specifically, Information and Communication Technologies (ICT) related higher education studies have suffered a decrease in the incoming students from Secondary Education in the last years. Several initiatives are being carried out, mainly in the western countries, to promote the technological and engineering vocations. In ETSETBTelecom BCN, the Telecom and Electronics Engineering School of Universitat Politècnica de Catalunya (UPC), placed in Barcelona, an existing modular remote laboratory platform [1] has been adapted to provide remote access to real experiments to Secondary Education students, as a way to increase their technological knowledge and skills but also to promote the interaction between the Secondary Education students and teachers and the University.

Remote laboratories are usually developed to enhance the conventional educational experiences and to optimize the use of resources [2], [3]. Leaving aside virtual laboratories based only on simulation, there is a considerable amount of remote laboratories that provide real-time access to real instruments. There are educational research lines devoted to the study of this topic [4]. Most of the remote labs for engineering education are in control [5],[6],[7] and electronics or circuit theory [8],[9],[10] areas. A good review of developments in the systems engineering area can be found in [11]. The aim of remote laboratories could be to provide complementary learning tools but also to provide facilities to access to big or singular equipments [12] or even to fully implement the laboratory activities [13]. Two literature reviews can be found in [14] and [15].

Almost all remote laboratories which have been reported have been designed and implemented to be used in the University frame. Meanwhile, Primary and secondary school students and teachers have access to a vast amount of internetbased resources. In our knowledge, almost all of them are virtual demonstrators, which are usually based on Java applets or flash animations, and very few of them are based on remote laboratories with real experiments [16], [17].

The remote laboratory described in this communication was initially designed to fulfill the needs of an advanced course in Electronics Engineering. However, it has been adapted to provide formative activities to Secondary School students. It has been possible thanks to the collaboration between the Telecom BCN staff, which includes our faculties, granted students and the IT staff, and Francesc Garófano, a Secondary Education teacher that spent a full sabbatical year in the development of both technical and didactical aspects of the remote laboratory.

In this communication we will mainly describe the non reported pilot experience that was carried out in 2008 with seven High Schools, involving around 100 students.

Nowadays, work is focused on developing new experiments, building more replicas of existing experiments and designing a complete software application to manage access to resources in terms of organization, security and accessibility.

\section{REMOTE LABORATORY}

iLabRS has been built over our custom modular platform [1] to develop remote laboratories in the instrumentation and sensors field. It is based on a main board that one of its functionalities is to provide a custom acquisition system around an Ethernet-capable microcontroller. The specific experiment circuit boards $(10 \times 10 \mathrm{~cm})$ are connected to the corresponding main board in a sandwich structure (Figure 1). 


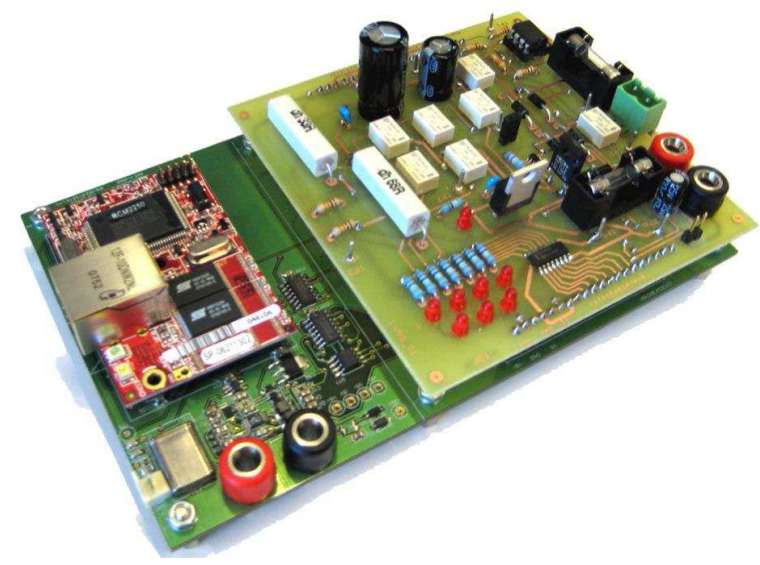

Figure 1. A main board with the experiment board 2 connected on its top. It implements a configurable linear power supply.

The main board has a single $5 \mathrm{~V}$ input power supply and provides $+/-5 \mathrm{~V}$ to the daughter board. The connection between both cards also include $4 \mathrm{~A} / \mathrm{D}$ and $\mathrm{D} / \mathrm{A}$ channels, $8 \mathrm{I} / \mathrm{O}$ bits and a selectable serial bus (SPI/I2C). iLabRS structure consists of several main boards, each of them with its own IP address, connected into a LAN through a switch with a dedicated server. This server is in charge of running the NI - LabView programs which implement the user interface and control. Teachers or students can perform experiments using a web browser to access to the iLabRS web site (http://ilabrs.etsetb.upc.edu), which contains didactic materials for each experiment and also the url to the LabView remote panel (Figure 2) which gives the control of the experiment.

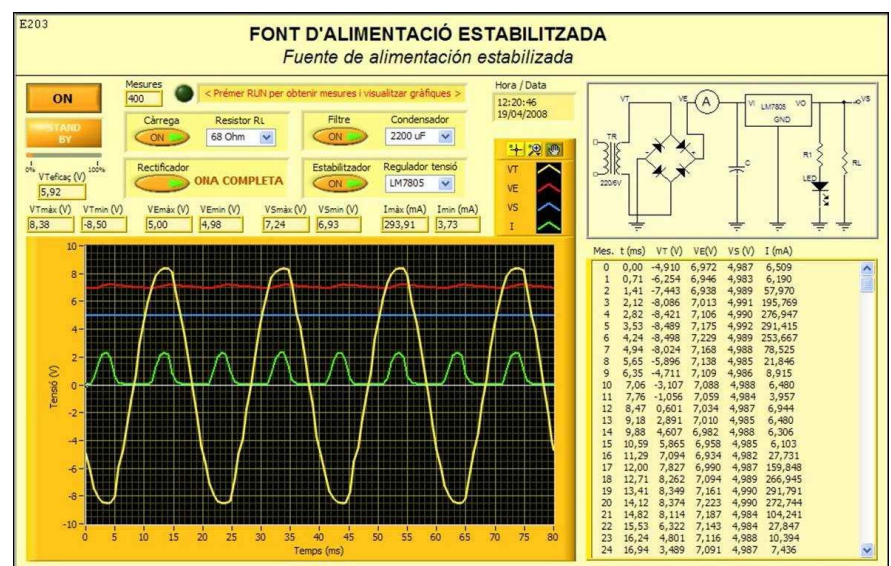

Figure 2. Remote panel corresponding to an experiment which deals with a regulated power supply. The students can see the schematic with the voltage and current symbols and read their instantaneous and time series. Several parameters (filter capacitor, load resistor) can be changed and the circuit configuration (half/full wave rectifier, insert regulator) can be selected.

At this time, up to 13 remote experiments corresponding to the Technology curricula of the two last High School years can be performed. Figure 3 shows the 10 boards that implement these experiments. There are three boards that can implement several experiments each one, and which are replicated three times. Experiments have been replicated because usually in High Schools all the students are moved to the computer room to perform a guided session by the teacher around one or two remote experiments while in the university courses are mainly used by the individual students from their homes. An additional board (left of the figure 3 ) implements a singular experiment (strain - stress measurement). The currently available experiments list is the following:

- Board 1: I/V characteristic curve of a resistor, silicon diode, germanium diode, LED and zener diode, all of them both in direct and inverse polarization. The experiment consists of performing a voltage sweep from $-5 \mathrm{~V}$ to $5 \mathrm{~V}$ through a resistor. Also includes a capacitor's charge and discharge process and time constant RC concept.

- Board 2: Basic linear power supply circuit. Components are a full/half wave diode rectifier, capacitor filter and a linear voltage regulator. Activities involve voltage and current measurements for different load resistor and filter capacitor values to determine ripple, linear regulator drop-out,..

- Board 3: Implements a basic transistor circuit characterization. It is possible to measure input and output characteristics, load line, operating point and gain. Input and output circuit resistors and voltages can be changed at any time and the device under test also can be switched between a signal and a power transistor.

- Board 4: Strain-stress characteristic of a polymer sample. The experiment controls a linear stepper motor and measures the output signal of a displacement and a force sensor. The motor can be operated manually or set in an automatic mode to obtain the up and down strainstress characteristics of the sample. Proposed students activities consist of determining force constant using Hooke's law and determining hystheresis among others.

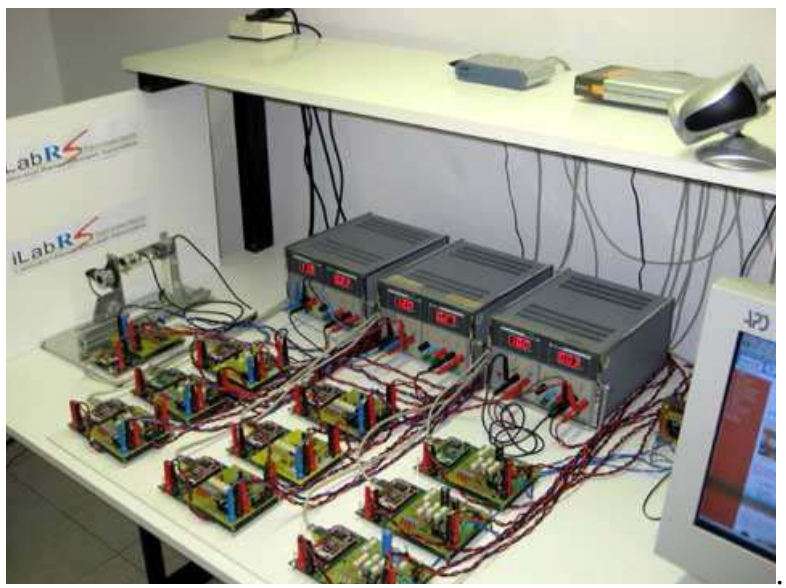

Figure 3. Remote laboratory current set of boards. It includes 10 main boards and 3 replica of 3 different experiment boards performing 12 different experiments on basic electronics plus a singular one (left) which measures the strain-stress characteristic of a polymer sample.

Once a given experiment is selected in the web page, the user gets the remote panel on his computer and takes the control of the LabView application (Vi, Virtual instrument) associated to this specific replica of the experiment. At the 
beginning, the Vi configures the board to select the circuit by switching relays which is transparent to the user. Then, the user selects the parameter values and circuit configuration (e.g. in the regulated power supply circuit, the filter capacitor and load resistor can be changed between three values each, and the circuit configuration (half/full wave rectifier, regulator inserted or not) can be selected). The main circuit node's signals are depicted in the schematic included in the panel, which can be monitored in three ways: instantaneous value, time series and graphical representation. In the first view of the panel, all signals are represented together. The individual signals can be seen more detailed (autoscaled) by scrolling the panel.

The didactic experiment guides include several documents: the experiment background review, the panel's user manual, the suggested set-up and a set of questions that student should answer using the obtained results. Usually, the student should paste these data to spreadsheet program to perform calculations (e.g. power from voltage and current, determination of slopes, etc.). At the end of the didactic guide, there is a set of additional questions.

\section{PILOT EXPERIENCE}

Seven High Schools from around Catalonia were selected and their Technology teachers were contacted. The amount of students of their Technology subjects in the two last years of High School was around 100. All of them were invited to visit the physical laboratory that supports the remote experiments in a specific Telecom BCN School Open Doors day. This was a good activity, useful not only to increase the feeling of reality of the remote lab but also to show the students the School laboratories and facilities and even the research activities. During the last term of year 2008, they performed classes based on the remote lab, mainly using two modalities: taking the whole group to the computer room and carrying out the experiences described in the didactic guides or using the experiments as demonstrators in the classroom using a projector (Figure 4).

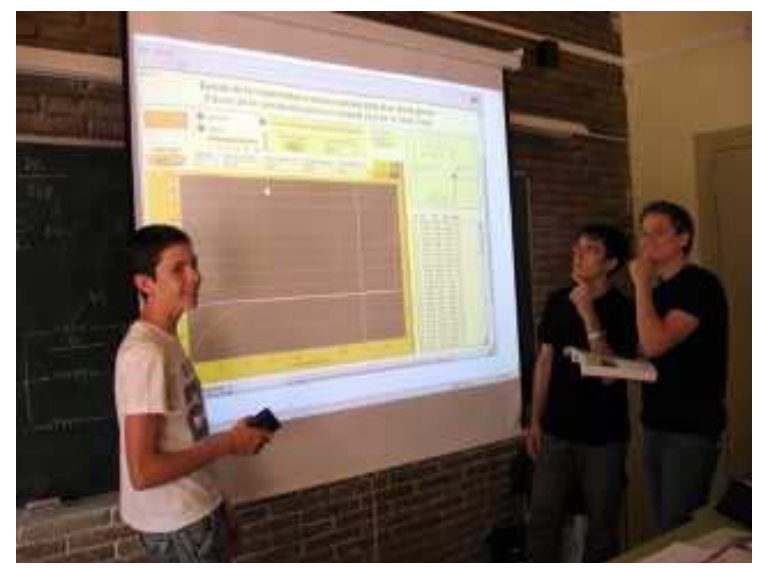

Figure 4. Students using the remote lab as demonstrator in the classroom in their High School

Not all the High Schools performed all the experiments, but they were asked to present the reports they made to a contest. The first, second and third winners received an award consisting in a technological gadget.
At the end of the term, the teachers and students were asked to fill a survey through a web page. The survey contained eight questions with a quantitative answer (1-low to 5-high) and five questions with an open, written answer. Table I shows the marks given by the first 8 questions. The experience was well valued, mainly by the teaching staff, as it could be expected.

TABLE I. RESULTS OF THE SURVEY

\begin{tabular}{|l|l|r|r|}
\hline$\#$ & Question & \multicolumn{1}{|l|}{ Std. } & Teach. \\
\hline 1 & Ease of use & 3,4 & 4,3 \\
\hline 2 & Appreciation of the experiments & 3,7 & 4,3 \\
\hline 3 & Appreciation of the documentation & 3,8 & 4,5 \\
\hline 4 & $\begin{array}{l}\text { Is this resource useful to improve the } \\
\text { experimental learning? }\end{array}$ & 4,0 & 4,5 \\
\hline 5 & $\begin{array}{l}\text { Appreciation of the remote lab as an } \\
\text { innovative resource }\end{array}$ & 4,0 & 4,5 \\
\hline 6 & Perspectives of future & 4,0 & 4,5 \\
\hline 7 & Personal satisfaction & 3,6 & 4,5 \\
\hline 8 & Global appreciation of the remote lab & 3,9 & 4,5 \\
\hline & Average & 3,8 & 4,45 \\
\hline
\end{tabular}

Concerning the qualitative answer questions, their responses were grouped by similarity. The most representatives are the following:

Q1. Which is the aspect that you consider more positive and practical of the remote lab?

- Being able to work in teams in a different way than usual.

- Being able to see the graphical results in real time during the class.

- The feeling that what you are simulating is really there and the fact that is not virtual, nor calculations.

Q2. Which is the aspect that you consider more negative and less effective of the remote lab?

- The limitation of a single simultaneous user in some experiments.

- The fact that the pilot experience has been performed at a point in the course which was not the most suitable.

- The limitation of getting only a limited set of values of a few variables.

Q3. Which aspects can be improved?

- An increase in the number if simultaneous users.

- The experiments should have a higher number of parameters to be changed. 
- The aesthetical aspects of the panels, the availability of the lab, the extent of the documentation.

Q4. Suggest please new experiments:

- Digital electronics and experiments on other technological fields (mechanics, hydraulics, robotics, magnetism...).

- Experiments with continuous changes in the parameter values, i.e. not only a few discrete values for the resistors.

- Measurement of voltages and currents in more complex DC circuits. AC and transient measurements in RLC circuits.

\section{Q5. Global comments:}

- The experience has been positive both for the students and teachers. It has improved the student's attitude.

- It has helped to reinforce the theoretical explanations.

- The experience is innovative and should be improved and augmented in the future

\section{CURRENT WORK}

Several tasks have been carried out this last year and a lot more are under development. The whole laboratory was moved to a more suitable location and the software was transferred to a new and more powerful server. An IP camera is connected in order to have a visual confirmation of the experiences, even when the only mobile part is the strain-stress experiment. At the beginning of year 2009, the lab received a grant from the Catalan government, together with other experiences that should increase the scientific and technologic vocations. Thanks to that, new experiments are being developed: a robotic arm whose movements can be programmed in real time or following a sequence, an hexapod robot based on shape memory alloy (Stiquito), an experiment to measure the efficiency of different lamps, an experiment to visualize the spectra of different light sources, ... Also more replicas (5) of the existing experiments are being built. Given that users can hold the panel's control for several minutes but in fact the real usage of the hardware resource is short (usually of around 10s periods), we are developing "virtual replicas", which allow sharing a given board between several panels, using concurrence and event control.

More complete software it is under design to manage the secure access and the resource organization for large groups. It also includes a resource booking tool to allow teachers to book a full set of experiments for a given slot of time. In addition, there is a control layer which manages the dynamic creation of remote panels under demand and the dynamic assignment of hardware boards to these panels. At this time, iLabRS is currently working and several High Schools are using it. A second promotion campaign will be carried out in January 2010, when the current improvements are planned to be finished, tested and validated.

\section{CONCLUSIONS}

An existing, modular platform to build remote laboratories at the Telecom BCN Engineering School has been used to implement a remote laboratory oriented to Secondary School Technology subjects. The main aim was to increase their technological knowledge and skills but also to promote the interaction between the Secondary Education students and teachers and the University. Thirteen different experiments were implemented and a pilot test was carried out with around 100 students from 7 High Schools. The results have allowed us to face a second phase, with improvements in both the experiments and the control software. The users' evaluation of the experience was clearly satisfactory.

\section{ACKNOWLEDGMENT}

Francesc Garófano has devoted a sabbatical year paid by the Education Department of Generalitat de Catalunya to develop this project. The second phase of the project has a grant from EnginyCAT project, SOC-FSE. The authors wish to acknowledge all people that have worked in this project and the teachers and students who have taken part in the pilot experience.

\section{REFERENCES}

[1] B. Sánchez, R. Bragós. "Modular workbench for in-situ and remote laboratories". IMTC'07. IEEE Instrumentation and Measurement Technology Conference. Warsaw 1-3 May 2007

[2] D. Grimaldi, S. Rapuano, T. Laopoulos. "Aspects of traditional versus virtual laboratory for education in instrumentation and measurement" IMTC'05 Conference, Ottawa 2005.

[3] H.A. Latchman, Ch. Saltzmann, D. Gillet, H. Bouzekri. "Information Technology Enhanced Learning in Distance and Conventional Education". IEEE Transactions on Education. Vol. 42, No. 4, pp247254, November 1999.

[4] C. Salzmann, H.A. Latchman, D. Gillet, O.D. Crisalle. "Requirements for real time laboratory experimentation over the internet". International Conference on Engineering Education, ICEE. Rio de Janeiro, Brazil, 17201998.

[5] B. Aktan, C.A. Bohus, L.A. Crowl "Distance learning applied to control laboratories". IEEE Transactions on Education. Vol. 39, No. 3, pp. 320326, 1996.

[6] M. Casini, D. Prattichizzo, A. Vicino. "The automatic Control Telelab : a remote control Engineering Laboratory." IEEE Conference on Decision and Control, Florida, USA, December 2001.

[7] J. Henry. "LabView applications in teaching control systems laboratories". ASEE, Anaheim, CA, USA. June 1995.

[8] H. Shen, Z. Xu, B. Dalager, V. Kristiansen, O. Strom, M.S. Shur, T.A. Fjeldly, J. Lu, T. Ytterdal. "Conducting Laboratory Experiments over the Internet". IEEE Transactions on Education, Vol. 42, No. 3, pp. 180185, August 1999.

[9] A. Etxebarria, I. Oleagordia M. Sánchez, "Power electronics and basic electronics real experiments through the World Wide Web" Frontiers in Education, Reno USA, 2001.

[10] I. Gustavsson. "Laboratory experiments in distance learning". International Conference on Engineering Education. Oslo, Norway, August 6-10, 2001.

[11] F.A. Candelas Herias and J. Sánchez Moreno. "Recursos didácticos basados en internet para el apoyo a la enseñanza de materias del área de ingeniería de sistemas y automática". Revista Iberoamericana de Automática e Informática industrial. Vol.2, Num. 2, pp. 93-101, 2005.

[12] F. Cennamo et al. "A remotely controlled measurement system for education and training of experiments in wind tunnel". IMTC'04 conference. Como, 2004. 
[13] S. Rapuano, F. Zoino "A learning management system including laboratory experiments on measurement instrumentation". IEEE Trans. Inst. Meas. Vol. 55, No. 5, pp. 1757-1766. 2006.

[14] J. Ma and J.V. Nickerson, "Hands-On, Simulated, and Remote Laboratories: A Comparative Literature Review," ACM Computing Surveys, vol. 38, 2006.

[15] E. Lindsay, P. Long, and P.K. Imbrie, "Remote Laboratories: Approaches for the Future," Proc. 37th ASEE/IEEE Frontiers in Education Conf., 2007.
[16] D.van Schenk Brill and B.van Gestel. "Students' appreciation of an online lab-experiment - A case study". SEFI, 37th annual conference on engineering education. Rotterdam, July 2009

[17] S. Paladini, J.B. da Silva, G.R. Alves, B.R. Fischer, J.B. da Mota Alves. "Using Remote Lab Networks to Provide Support to Public Secondary School Education Level". 11th IEEE International Conference on Computational Science and Engineering Workshops, 2008. Sao Paulo, 16-18 July 2008. Pp. $275-280$ 
